\title{
EFEITO DA LUMINOSIDADE E DA ADIÇÃO DE NITROGÊNIO NO CRESCIMENTO DE PLANTAS DE Ilex paraguariensis St. Hil. ${ }^{1}$
}

\author{
Jorge Zbigniew Mazuchowski², Eduardo Teixeira da Silva ${ }^{3}$ e Agenor Maccari Junior ${ }^{3}$
}

\begin{abstract}
RESUMO - Neste trabalho, buscou-se identificar o efeito de diferentes níveis de luminosidade e da adição de adubo nitrogenado sobre o crescimento das plantas de erva-mate, no primeiro ano de crescimento. No experimento, usou-se o delineamento de blocos ao acaso, com três repetições, em quatro tratamentos e dois subtratamentos, tendo 16 parcelas por bloco. O esquema adotado foi o fatorial, tendo como variável constante a luminosidade em quatro intensidades $(100,70,50$ e 30\%) e o nitrogênio como variável interveniente sobre as parcelas. As leituras foram efetuadas a cada 45 dias, em três horários diários por três dias consecutivos, durante um ano. Verificou-se que a condição mais adequada para o crescimento das plantas foi com luminosidades de 50 e 30\%. A adição de nitrogênio não mostrou influência relevante no crescimento da erva-mate, especialmente nas luminosidades de 100 e $70 \%$, enquanto o aumento da luminosidade tendeu a reduzir o crescimento das plantas. Contudo, as plantas adubadas $(1 \mathrm{~N})$ tiveram maior rebrota que aquelas não-adubadas. A adição de nitrogênio mineral, em dosagens elevadas, foi danosa para as plantas de erva-mate, acarretando a mortalidade nas parcelas com tratamentos de maior luminosidade.
\end{abstract}

Palavras-chave: Ilex paraguariensis, luminosidade e crescimento.

\section{EFFECT OF LIGHT AND NITROGEN ON THE GROWTH OF Ilex paraguariensis St. Hil.}

\begin{abstract}
This paper aimed to evaluate the effect of different levels of luminosity and nitrogen addition on the height of mate plants in the first year of growth. The experiment was arranged in randomized blocks, with three replicates, in four treatments and two sub-treatments, in a total of 16 plots per block, in a factorial design, with the luminosity in four different intensities (100\%, 70\%, 50\% and 30\%) and the nitrogen application as the intervening variable on the plots. Data were collected every 45 days, in three daily schedules during three consecutive days, over one year. It was found that the best conditions to plant growth were 50\% and $30 \%$ luminosity. The nitrogen addition have no relevant influence in plant growth, particularly at $100 \%$ and $70 \%$ luminosity, while the increase in luminosity contributed to the reduction in plant growth. However, the fertilized plants $(1 N)$ increased regrowth. Nitrogen addition at high doses damaged the mate plants and caused death of mate plants in the plots with higher luminosity.
\end{abstract}

Keywords: Ilex paraguariensis, light and growth.

\footnotetext{
${ }^{1}$ Recebido em 19.09.2006 e aceito para publicação em 29.03.2007

${ }^{2}$ EMATER-Paraná. Rua Padre Osvaldo Gomes 454-B (Guabirotuba) 81.510-100 Curitiba-PR. Tel. (0xx41) $3296-6773$. E-mail:<mazuchowski@netpar.com.br>.

${ }^{3}$ Departamento de Solos e Engenharia Agrícola da UFPR. Rua dos Funcionários, 1540 (Juvevê). 80.035-050 Curitiba -PR. Tel. (0xx41) 3350-5667.E-mail: <eduardo@ufpr.br>e <maccari@ufpr.br>.
} 


\section{INTRODUÇÃO}

A erva-mate (Ilex paraguariensis St. Hil.) é caracterizada como espécie florestal umbrófila e seletiva higrófila que cresce preferencialmente em associações mais evoluídas dos pinheirais de Araucaria angustifolia, acompanhada de outras espécies de mirtáceas, leguminosas diversas e lauráceas (CARVALHO, 1994). Apresenta ocorrência natural mais freqüente em solos com textura média e textura argilosa, preferem solos medianamente profundos a profundos e não ocorrem em solos rasos, além de vegetar preferencialmente em solos com umidade típica das regiões com clima do tipo Cfb (OLIVEIRA e ROTTA, 1985).

Na descrição botânica de Kricun (1983) e Giberti (1995), constitui árvore perenifolia, com altura variável de 3 a $5 \mathrm{~m}$ (em plantios manejados) até $25 \mathrm{~m}$ de altura e diâmetro de $70 \mathrm{~cm}$, em ambiente florestal nativo. $\mathrm{O}$ tronco é cilíndrico, reto ou tortuoso; racemosa, quase horizontal; copa baixa, densifoliada, com folhagem verdeescura característica. As folhas são simples e alternas, estipuladas, subcoriáceas e até coriáceas. As flores são brancas e pequenas, em inflorescências de pequenos fascículos com até cinco flores, em ramos velhos na axila foliar. $O$ fruto é uma drupa globosa de 4 a $6 \mathrm{~mm}$ de diâmetro, com superfície lisa, cor violácea a preta, tetralocular com quatro sementes de polpa mucilaginosa.

A estrutura da planta de erva-mate responde diretamente às condições ambientais, como intensidade luminosa e teores de nutrientes, podendo alterar sua morfologia e seus processos fisiológicos (FOSSATI, 1997). Os efeitos da intensidade luminosa e do sombreamento relativos ao crescimento e desenvolvimento das plantas já foram estudados em outras espécies, como café (FAHL e CARELLI, 1994) e palmito (NAKAZONO et al., 2001), sendo a luz solar essencial no seu processo de fotossíntese, cuja intensidade e duração devem ser suficientes para o crescimento das plantas (DA CROCE e FLOSS, 1999).

Geralmente apresenta dominância apical definida e rebrota satisfatória após o corte dos ramos, desde o colo ou de altura mais elevada, com cortes anuais ou a cada dois anos (CARVALHO, 1994; FLOSS et al., 2000; MAZUCHOWSKI, 2001). As plantas de sub-bosque ou sombreadas alteram sua espessura foliar quando colocadas a pleno sol, porque a água, o solo e a intensidade luminosa influenciam também a sua estrutura foliar (BOEGER et al., 2003).

R. Árvore, Viçosa-MG, v.31, n.4, p.619-627, 2007
Em relação à luminosidade, a erva-mate é caracterizada como planta esciófila, aceitando sombra em qualquer idade, embora tolere mais luz na fase adulta, além de ser tolerante ao frio (CARVALHO, 1994). Kaspary (1985) verificou valores superiores de área foliar, altura da planta e produção de massa de matéria seca de plantas jovens sob condições de sombreamento, tendendo à redução com o aumento da intensidade luminosa de 20 para $60 \%$, embora o número de ramificações e a taxa fotossintética tenham sido superiores no tratamento com plena luz. Rakocevic et al. (2003) verificaram que a erva-mate responde à sombra, primeiramente como espécie que compete pela luz (alongando o caule e aumentando a área foliar). Contudo, no limite mínimo de luminosidade a planta se adapta preservando o seu funcionamento, efetuando aumento de área foliar por folha e reduzindo a emissão de novas folhas e a altura do caule, de forma a esperar as condições de radiação mais favoráveis, as quais normalmente ocorrem na abertura de uma clareira. Outros estudos compararam as características morfológicas entre folhas sob diferentes intensidades luminosas (ASTHON e BERLYN, 1992; SIMS e PEARCY, 1992; BOEGER et al. 2003), evidenciando-se as modificações na espessura das folhas em consequência da densidade estomática, espessura da cutícula e pubescência, entre outras.

O manejo sustentável de floresta secundária com erva-mate pelo sistema de extratos permite ter sombra e luminosidade adequadas pelo manejo das copas de árvores, com redução no número de ramos e folhas, sendo variável em cada espécie florestal mantida (DA CROCE e FLOSS, 1999). As árvores com copas mais frondosas e elevadas requerem espaçamentos maiores comparativamente àquelas que são mais baixas e que têm copa pequena. Para a introdução do sombreamento nos ervais comerciais, deverão ser atendidos esses requisitos das espécies florestais manejadas com ervamate, visando ao bom controle de luminosidade e sombra (DASILVAe MAZUCHOWSKI, 1999; MAZUCHOWSKI, 2001).

Estudos da senescência em espécies arbóreas são escassos, principalmente de espécies subtropicais ou temperadas. Segundo Reich (1995), em florestas de climas com chuvas escassas, em média, cerca de $80 \%$ das espécies perdem suas folhas aos oito meses de idade, enquanto nas florestas tropicais aproximadamente $2 / 3$ das espécies possuem longevidade foliar superior a 16 meses. Num experimento da EPAGRI, verificou-se que 
um dos principais fatores para a maior longevidade foliar da erva-mate nativa foi o sombreamento, por encontrar-se em sub-bosque de floresta secundária (FLOSS et al., 2000).

Na implantação dos ervais, Medrado et al. (2000) recomendaram a adubação em covas com a adição de esterco orgânico misturado com terra, podendo ser acrescido de $60 \mathrm{~g}$ de adubo químico, na fórmula NPK 10-20-10. Lourenço (1997) analisou a produtividade de erveiras adultas em Fernandes Pinheiro, PR, em três safras seqüenciais de ano e meio, concluindo que a cobertura morta é altamente recomendável, enquanto a adubação nitrogenada com uréia ou sulfato de amônio é preconizada especialmente para plantios em solos de textura média.

A adubação para plantio pode, no entanto, ser corretiva na área toda ou em parte dela, ou apenas como adubação de arranque, aplicada na cova, quando se procura auxiliar a adaptação das mudas às condições do terreno local. Para dar o arranque inicial das mudas de erva-mate, especialmente nos dois anos iniciais, é importante uma adubação com condicionador orgânico (LOURENÇO, 1997).

O objetivo deste trabalho foi estabelecer o efeito de diferentes intensidades luminosas sobre o crescimento em altura e área foliar total das plantas de erva-mate, nos estágios iniciais do primeiro ano, combinados com a adição de nitrogênio mineral.

\section{MATERIAL E MÉTODOS}

O experimento com mudas de erva-mate foi instalado em agosto de 2002 na Universidade Federal do Paraná (UFPR), em Curitiba, região do $1^{\circ}$ Planalto do Estado do Paraná, altitude próxima de $900 \mathrm{~m}$, latitude de $25^{\circ} 12^{\prime} \mathrm{S}$ e longetude de $49^{\circ} 6^{\prime} \mathrm{W}$, com clima do tipo Cfb, segundo a classificação de Köeppen (clima subtropical úmido sem estação seca, com verão fresco, onde a temperatura média do mês mais quente fica abaixo de $22^{\circ} \mathrm{C}$ ).

Naárea experimental de $20 \mathrm{~m} \times 36 \mathrm{~m}$ foram implantados três blocos, com quatro tratamentos (graus de luminosidade de $70 \%, 50 \%, 30 \%$ e $0 \%$ ) e quatro subtratamentos (doses de nitrogênio de $0 \mathrm{~N}, 1 \mathrm{~N}, 2$ $\mathrm{N}$ e $3 \mathrm{~N}$ ) em cada um deles, num total de 16 parcelas por bloco. Cada parcela foi composta por 12 plantas de erva-mate, sem bordadura. O delineamento empregado foi o de blocos casualizados no esquema fatorial, sendo a luminosidade em quatro diferentes intensidades a variável constante e a aplicação de nitrogênio como a variável interveniente.

Para avaliação do efeito do nitrogênio na ervamate, empregou-se o sulfato de amônio, aplicado em dose única, ao redor das mudas, aos 90 dias de campo, em janeiro de 2003, com umidade relativa do ar ao redor de $44 \%$, em período desfavorável. Optou-se pela aplicação de $50 \%$ da dosagem empregada em plantas de idade superior a 5 anos (em fase produtiva), no subtratamento com $1 \mathrm{~N}$, por ser adubo mineral. Conseqüentemente, os quatro subtratamentos apresentaram parcelas sem aplicação $(0 \mathrm{~N})$ e com adição de nitrogênio na embalagem ( $1 \mathrm{~N}$ com $25 \mathrm{~g}, 2 \mathrm{~N}$ com $50 \mathrm{~g}$ e $3 \mathrm{~N}$ com $75 \mathrm{~g}$ ).

A coleta de frutos de erva-mate foi realizada em árvores-matriz da Fazenda Nova, da Indústria Ervateira Bitumirim, Município de Ivaí, PR. Após a maceração dos frutos colhidos para obtenção das sementes, foi efetuada a semeadura direta em sacos de polietileno preto-opaco de $18 \mathrm{~cm}$ x $6 \mathrm{~cm}$. As mudas atingiram condições de plantio definitivo, em número de folhas e diâmetro de colo, no final de agosto do mesmo ano. As mudas foram transplantadas para sacos de polietileno preto-opaco de $15 \mathrm{~cm}$ x $30 \mathrm{~cm}$, com perfurações laterais drenantes e capacidade para $8 \mathrm{~kg}$ de substrato-solo, garantindo a sustentação durante um ano. Cada parcela era composta por 15 plantas de erva-mate.

Como substrato, utilizou-se solo definido como Organossolo háplico (anteriormente denominado Solo Orgânico), de acordo com a Classificação Brasileira de Solos (EMBRAPA, 1999), contendo $250 \mathrm{~g} \mathrm{~kg}^{-1} \mathrm{de}$ argila e $150 \mathrm{~g} \mathrm{~kg}^{-1}$ de areia. A média dos resultados da análise química indicou $\mathrm{pH}(\mathrm{CaCl} 2)$ : 4,80; $\mathrm{Al}+++$ : $1,30 \mathrm{cmol} \mathrm{dm}^{-3} ; \mathrm{H}+\mathrm{Al}: 11,30 \mathrm{cmol} \mathrm{dm}^{-3} ; \mathrm{Ca}(++)+\mathrm{Mg}(++)$ : 9,20 $\mathrm{cmol} \mathrm{dm}^{-3} ; \mathrm{Ca}(++): 6,00 \mathrm{cmol} \mathrm{dm}^{-3} ; \mathrm{K}+: 0,20 \mathrm{cmol}$ $\mathrm{dm}^{-3}$; C: $46,20 \mathrm{~g} \mathrm{dm}^{-3}$; P: $22,00 \mathrm{mg} \mathrm{dm}^{-3}$; V: 44,28 $\%$; e T: $20,28 \mathrm{cmol} \mathrm{dm}^{-3}$.

Para estabelecer as condições de luminosidade solar desejada, foi montada uma estrutura de $4 \mathrm{~m}$ de altura, composta por palanques de madeira de bracatinga (Mimosa scabrella Benth.) e com cabos de aço, sobre a qual foram fixadas três diferentes mantas de Polysombra Difusora $(70 \%, 50 \%$ e $30 \%$ de efeito redutor da luminosidade), as quais, juntamente com a testemunha, geraram quatro tratamentos, simulando as condições de luminosidade e sombra da natureza, além de estabelecer uniformidade em cada parcela.

R. Árvore, Viçosa-MG, v.31, n.4, p.619-627, 2007 
Realizado a cada ciclo de 45 dias, o monitoramento dos aspectos climáticos baseou-se em três horários diários $(9,12$ e 15 h) em três dias consecutivos, estabelecendose uma média de oito períodos climáticos, com vistas à obtenção de dados sobre a luminosidade incidente nas plantas, a umidade relativa do ar, a temperatura do solo a 10 e $5 \mathrm{~cm}$ de profundidade nas embalagens com mudas e a temperatura máxima do ar. Nesse sentido, em cada parcela empregou-se o luxímetro digital para as leituras de luminosidade solar, com medições no colo e ápice das plantas, enquanto em cada tratamento se utilizaram psicrômetro para a medição da umidade relativa do ar e termômetros de mercúrio para verificação das temperaturas do solo a $5 \mathrm{~cm}$ e $10 \mathrm{~cm}$ de profundidade do substratosolo, aliado ao termômetro de máxima e mínima para obtenção da temperatura máxima do ar.

Em paralelo, efetuaram-se aferições do crescimento das plantas de erva-mate, com mensurações individuais de cada planta, visando obter parâmetros específicos de altura média (mensuração com régua graduada), quantidade de folhas em cada planta (mediante a contagem por indivíduo) e área da superfície foliar de cada planta (após o corte do caule e ramos, com utilização de scanner de mesa acoplado a computador dotado de programa WinRhizzo, no Laboratório de Análises de Plantas do Departamento de Fitotecnia da Universidade Federal do Paraná). As medições das plantas foram efetuadas em intervalos de três meses, de forma a obter indicadores de cada estação climática.

Os resultados parciais coletados, referentes a aspectos climáticos e ao crescimento das plantas de erva-mate, foram submetidos à análise estatística pelo programa "Sirichai's Statistics" e ao teste de Duncan para níveis de variância e significância dos dados.

\section{RESULTADOS E DISCUSSÃO}

\subsection{Aspectos Microclimáticos do Ambiente}

Dentre os parâmetros microclimáticos coletados nas oito séries de monitoramento ambiental do experimento, foram selecionados os valores médios das estações climáticas de verão e inverno (Tabela 1), por representarem duas fases características mais contrastrantes da cultura da erva-mate.

Os indicadores microclimáticos coletados no inverno demonstraram que as condições ambientais mais adequadas para o crescimento das plantas de erva-mate foram verificadas quando submetidas à redução da luminosidade do que aquelas submetidas diretamente às condições de sol direto (sem sombreamento), de forma similar aos referidos por Ferreira et al. (1994) e Vieira et al. (2003).

A intensidade luminosa verificada no ápice da planta foi de aproximadamente $20 \%$ superior àquela abservada no colo, independentemente de horário diário, grau de sombreamento decorrente da planta e da estação climática. Entretanto, a redução dos níveis de intensidade luminosa atinge valores de até $300 \%$ quando se analisam uma planta a pleno sol e outra em condições de $30 \%$ de luminosidade, em especial no horário das $9 \mathrm{~h}$, embora seja diferença menor nos demais horários de observação.

A menor intensidade luminosa durante o dia foi observada no horário das $15 \mathrm{~h}$, independentemente do grau de luminosidade estabelecido. Outrossim, verificouse estreita correlação entre os níveis de intensidade luminosa e as condições de temperatura do solo e umidade relativa do ar, determinando que o desenvolvimento vegetal mais apropriado ocorre nas condições de menor luminosidade, conforme também observado por Rakocevic et al. (2003).

Tabela 1 - Valores médios mensais da umidade relativa do ar, da temperatura do solo a 10 e $5 \mathrm{~cm}$ de profundidade, da temperatura máxima do ar e da luminosidade, no ambiente experimental, no verão (janeiro) e no inverno (julho), sob diferentes graus de luminosidade

Table 1 - Means of air relative humidity, soil temperature at 10 and $5 \mathrm{~cm}$ depth, maximum air temperature and luminosity, in the experimental conditions, in the summer (January) and winter (July), under different light gradients

\begin{tabular}{|c|c|c|c|c|c|c|c|c|c|c|}
\hline \multirow{3}{*}{$\begin{array}{c}\text { Grau de } \\
\text { Luminosidade } \\
(\%)\end{array}$} & \multirow{2}{*}{\multicolumn{2}{|c|}{$\begin{array}{c}\text { Umidade Relativa } \\
\text { do Ar } \\
(\%) \\
\end{array}$}} & \multicolumn{4}{|c|}{$\begin{array}{l}\text { Temperatura } \\
\text { do Solo }\left({ }^{\circ} \mathrm{C}\right) \\
\end{array}$} & \multirow{2}{*}{\multicolumn{2}{|c|}{$\begin{array}{c}\text { Temperatura } \\
\text { Maxima do } \\
\text { Ar }\left({ }^{\circ} \mathrm{C}\right)\end{array}$}} & \multirow{2}{*}{\multicolumn{2}{|c|}{$\begin{array}{c}\text { Intensidade } \\
\text { Luminosa } \\
(\text { Lux }) \\
\end{array}$}} \\
\hline & & & \multicolumn{2}{|c|}{ A $10 \mathrm{~cm}$} & \multicolumn{2}{|c|}{ A $5 \mathrm{~cm}$} & & & & \\
\hline & JAN. & JUL. & JAN. & JUL. & JAN. & JUL. & JAN. & JUL. & JAN. & JUL. \\
\hline 30 & 91,38 & 83,93 & 18,6 & 16,7 & 19,7 & 15,8 & 21,5 & 20,3 & 10.600 & 26.378 \\
\hline 50 & 89,60 & 84,17 & 18,9 & 15,4 & 18,8 & 15,6 & 21,5 & 20,0 & 17.550 & 36.402 \\
\hline 70 & 77,84 & 80,20 & 19,4 & 16,0 & 19,6 & 18,0 & 21,0 & 19,6 & 20.755 & 46.034 \\
\hline 100 & 81,05 & 78,05 & 21,6 & 20,1 & 20,6 & 19,5 & 25,7 & 24,3 & 32.567 & 55.988 \\
\hline MEDIA & 84,97 & 81,65 & 19,6 & 17,0 & 19,7 & 17,2 & 22,4 & 21,0 & 20.368 & 41.201 \\
\hline
\end{tabular}

R. Árvore, Viçosa-MG, v.31, n.4, p.619-627, 2007 
Os dados médios de umidade relativa do ar, no horário das $12 \mathrm{~h}$, apresentaram o menor parâmetro diário, em qualquer época do ano e independente do tipo de luminosidade, basicamente em razão da intensidade da radiação solar. Já os parâmetros médios das 15 h demonstraram ser dependentes das condições climáticas ocorrentes no dia, em especial a influência local de ventos predominantes, resultando em dados intermediárias dos outros dois horários. Os parâmetros sob luminosidades de 30 e $50 \%$ foram bastante próximos entre si, embora superiores aos dos demais tratamentos, com diferenças variáveis entre 10 e $20 \%$.

$\mathrm{Na}$ análise das temperaturas de solo nas profundidades de $5 \mathrm{~cm}$ e $10 \mathrm{~cm}$, observaram-se diferenças marcantes nos dados que destacam a importância do sombreamento para a erva-mate. Quanto maior o grau de sombreamento decorrente da redução de luminosidade, menor a temperatura do solo, variando do horário matinal ao vespertino quando atinge os ápices diários. Foi superior nos meses mais quentes (oscilação ao redor de $1^{\circ} \mathrm{C}$ entre os tipos de luminosidade) e menor nos meses mais frios (ao redor de $0,4^{\circ} \mathrm{C}$ entre os tratamentos). A oscilação diária da temperatura do solo nos diversos tratamentos, comparativamente entre as duas profundidades analisadas, foi menor nas medições a $10 \mathrm{~cm}$ devido à maior estabilidade da temperatura, com variação mínima entre os graus de luminosidade.

Situação idêntica foi verificada com a temperatura máxima do ar, apesar da tendência de uniformização dos valores nos horários de 12 e $15 \mathrm{~h}$. As temperaturas mais baixas e frias da noite influenciaram, sobremaneira, os dados das 9 h. A temperatura do ar mais elevada foi verificada nas condições de pleno sol, enquanto a temperatura do ar mais baixa foi nas condições de $30 \%$ de luminosidade. Com 70 e $50 \%$ de luminosidade, os valores de temperatura são bastante similares, especialmente às 12 e $15 \mathrm{~h}$.

Pela análise de variância dos diversos parâmetros microclimáticos monitorados, verificaram-se diferenças estatisticamente significativas em relação ao mês do ano, mas não em relação ao material de sombreamento e à correlação entre material de sombreamento e época do ano.

\subsection{Altura das Plantas}

A altura é um parâmetro característico de avaliação das respostas de crescimento à intensidade luminosa, em face de a capacidade de crescer na sombra ser mecanismo relevante de adaptação das plantas, como na erva-mate (ENGEL, 1990). Em decorrência do desfolhamento ocorrido no período de outono-inverno, seguido da recuperação da área foliar na primavera, a altura média das plantas nos tratamentos de luminosidade com $100,70 \%$ e $50 \%$ ficou inalterada praticamente por um período de seis meses (Figura 1), observando-se na primavera crescimento em altura mais significativo nas parcelas sem adubação nitrogenada.

\section{Com Nitrogênio}

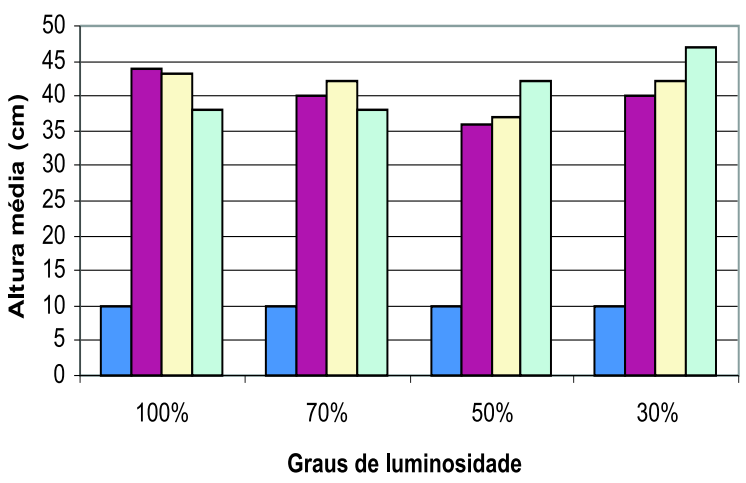

\section{Sem Nitrogênio}

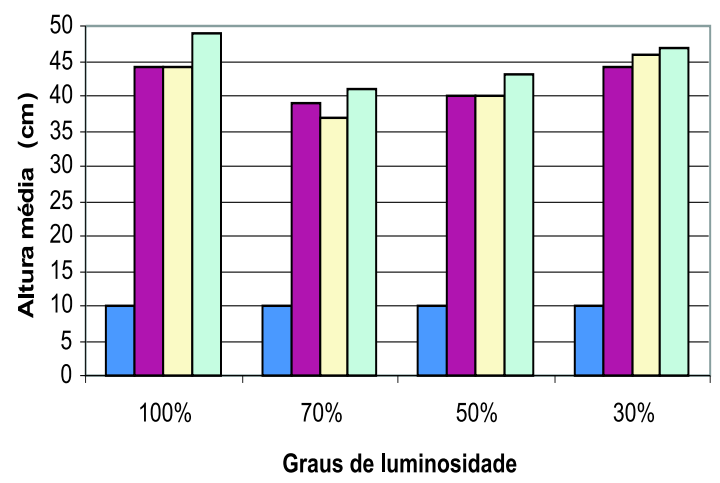

Figura 1 - Comparativo da variação das alturas médias das plantas de erva-mate, sob diferentes graus de luminosidade, com e sem adubação nitrogenada $(0 \mathrm{~N}$ e $1 \mathrm{~N})$, nas quatro estações climáticas.

Figure 1 - Comparison of variation in the mean height of mate plants under different luminosity gradients, with and without nitrogen addition $(O \mathrm{~N}$ and $1 \mathrm{~N})$, on the four seasons of the year. 
As plantas sem adição de adubo nitrogenado apresentaram crescimento superior em altura quando comparadas com as que receberam adubação nitrogenada, nos tratamentos com 50 e $30 \%$ de luminosidade, em todas as estações climáticas monitoradas (Tabela 2). Por sua vez, nos tratamentos com 100 e $70 \%$ de luminosidade os resultados foram equivalentes entre parcelas sem e com adubação.

A adição de nitrogênio no meio da estação de verão acarretou prejuízos às plantas de erva-mate, antecipando a maturação foliar seguida de desfolhamento e redução do crescimento apical. Nos tratamentos com $2 \mathrm{~N}$ e $3 \mathrm{~N}$ de adubação nitrogenada com sulfato de amônio, houve mortalidade das plantas nas parcelas correspondentes, ficando apenas os dados dos subtratamentos $0 \mathrm{~N}$ e 1 $\mathrm{N}$ para monitoramento e análise estatística.

Os dados de altura média das plantas de erva-mate foram todos iguais na estação do verão, em face do predomínio do desenvolvimento radicular, sem crescimento relevante em altura, verificado nas medições laboratoriais na parte aérea e radicular de plantas. Os dados de inverno apresentaram uma diferenciação de altura média nas plantas, de acordo com o grau de luminosidade (Tabela 2), e os maiores valores foram encontrados no tratamento com $30 \%$ de luminosidade, perante os indicadores menores do tratamento a pleno sol.

A adição de adubo nitrogenado na fase inicial de crescimento da erva-mate não apresentou ganho em crescimento do fator altura das plantas, para justificar essa prática agronômica, conforme observado nas coletas de inverno. Por sua vez, nos diversos graus de luminosidade observou-se comportamento inferior no crescimento das plantas com adição de nitrogênio, incluindo a queima dos botões terminais no outono e inverno, fator gerador de desfolha indesejada no período típico da erva-mate. Fossati (1997) relatou uma tendência inibitória desse nutriente para o incremento da área foliar, especialmente em dosagens elevadas, e os resultados deste trabalho vem corroborar essa relação.

De acordo com a análise de variância das médias de altura das plantas nas medições de verão e de inverno, verificaram-se diferenças significativas (teste F com $99 \%$ de significância) relativas aos tipos de sombreamento e à estação climática, enquanto os dados apresentaram pouca significância em relação à dosagem de nitrogênio aplicado e suas correlações.

R. Árvore, Viçosa-MG, v.31, n.4, p.619-627, 2007

\footnotetext{
R. Árvore, Viçosa-MG, v.31, n.4, p.619-627, 2007
}

Tabela 2 - Alturas médias das plantas de erva-mate sob diferentes graus de luminosidade na estação de inverno, independentemente da adição de nitrogênio

Table 2-Mean plant height under different shading gradients in the winter, independently of nitrogen addition

\begin{tabular}{|c|c|c|c|}
\hline \multirow{2}{*}{$\begin{array}{c}\text { Tratamento } \\
\text { (Luminosidade) }(\%)\end{array}$} & \multicolumn{2}{|c|}{ Altura Média das } & Plantas \\
\hline & $\mathrm{cm}$ & & $\%$ \\
\hline 30 & 43,25 & $\bar{a}$ & 147,46 \\
\hline 50 & 40,96 & b & 139,65 \\
\hline 70 & 40,87 & b & 139,35 \\
\hline 100 & 29,33 & $\mathrm{c}$ & 100,00 \\
\hline
\end{tabular}

C.V. de $38,60 \% 1$. Os valores de médias seguidas pela mesma letra não diferem, significativamente, pelo teste de Duncan a $5 \%$ de probabilidade.

\section{3. Área Total da Superfície Foliar}

Como a área foliar é uma característica para se analisar a tolerância à sombra das diferentes espécies de plantas, devido à sua correlação direta com a área da superfície fotossintetizante útil (ENGEL, 1990), os dados de aumento da área foliar decorrentes dos tipos de luminosidade evidenciaram a veracidade dessa afirmação.

Pelo emprego do Programa WinRhizo, demonstrouse que os dados médios da área total da superfície foliar foram maiores nas condições de maior sombreamento, reduzindo-se gradualmente à medida que aumentava $\mathrm{o}$ grau de luminosidade (Tabela 3).

Nas condições de primavera, observou-se que as luminosidades de 50 e $30 \%$ representaram as melhores condições ambientais para incremento da produtividade de biomassa foliar, confirmando as observações de aumento da área foliar de plantas quando submetidas à redução da luminosidade por Ferreira et al. (1994) e Rakocevic (2003). Os dados apontaram que a média da área foliar das plantas no verão foram estatisticamente equivalentes às de outono e inverno, apesar do incremento de $36 \%$ no crescimento foliar.

Com a chegada da primavera e o conseqüente aumento da temperatura e da luminosidade, as plantas voltaram a apresentar crescimento na superfície da área foliar. Referendando as observações de Ferreira et al. (1994) e Kaspary (1985), verificou-se uma média estatísticamente diferente em comparação com as dos dados de verão, com aumento de $66 \%$ na área foliar total (Tabela 4). No entanto, observou-se uma tendência de maior área foliar das plantas em condições de menor luminosidade (Figura 2) quando buscam mecanismos de compensação pelo aumento de sua área foliar, confirmando observações de Kaspary (1985), Boeger e Wisniewski (2002), Cavichiolo et al. (2003) e Boeger et al. (2003). 
Tabela 3 - Área foliar total média por planta de erva-mate, verificada através do Programa WinRhizo, independentemente da adição de adubação nitrogenada

Table 3 - Mean total leaf area surface in mate plants, using the WinRhizo software, independently of nitrogen addition

\begin{tabular}{ccccc}
\hline $\begin{array}{c}\text { Grau de } \\
\text { Luminosidade } \\
(\%)\end{array}$ & \multicolumn{4}{c}{$\begin{array}{c}\text { Área Foliar Total } \\
\text { Média por Planta }\left(\mathrm{cm}^{2}\right)\end{array}$} \\
\cline { 2 - 5 } & Verão & Outono & Inverno & Primavera \\
\hline 30 & 1.403 & 1.935 & 1.577 & 2.366 \\
50 & 1.359 & 1.396 & 1.693 & 2.208 \\
70 & 1.154 & 1.714 & 1.935 & 1.554 \\
100 & 1.071 & 1.756 & 1.396 & 2.143 \\
\hline MÉDIA & 1.247 & 1.701 & 1.650 & 2.068 \\
\hline
\end{tabular}

Tabela 4 - Incremento da média da área foliar total por planta de erva-mate nas quatro estações climáticas

Table 4-Increase in mean total leaf area surface of mate plants on the four seasons of the year

\begin{tabular}{|c|c|c|}
\hline Período & Área Foliar Total (mm 2) & Incremento $\%$ \\
\hline$\overline{\text { Primavera }}$ & 2067,96 a & 165,77 \\
\hline Inverno & $1701,01 \mathrm{ab}$ & 136,35 \\
\hline Outono & $1698,28 \mathrm{ab}$ & 136,14 \\
\hline Verão & $1247,50 \mathrm{~b}$ & 100,00 \\
\hline
\end{tabular}

Médias seguidas da mesma letra não diferem significativamente pelo Teste deDuncan a $5 \%$ de probabilidade.

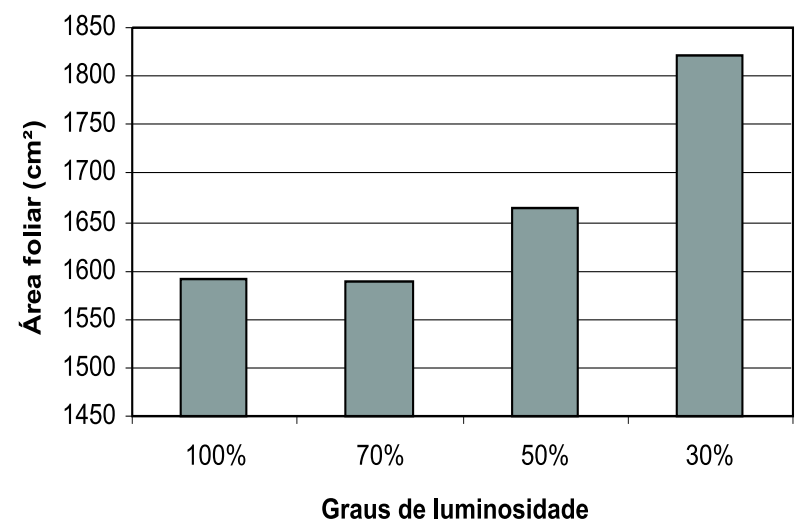

Figura 2 - Área foliar média em plantas de erva-mate, nas diferentes condições de luminosidade ambiental, independentemente da adição de adubo nitrogenado.

Figure 2-Mean leaf area of mate plants under different conditions of environmental luminosity, independently of the nitrogen addition.
Na mensuração do total de folhas por planta, a adição de nitrogênio na fase inicial de crescimento das plantas favoreceu o desenvolvimento foliar, especialmente na rebrota intensa das plantas com adubação nitrogenada ( $1 \mathrm{~N})$, comparativamente àquelas não-adubadas. A análise estatística dos dados coletados no verão e no inverno demonstrou diferenças estatisticamente significativas em relação ao tipo de luminosidade empregado.

\section{CONCLUSÕES}

A condição mais adequada ao crescimento das plantas de erva-mate foi obtida nas luminosidades de 50 e $30 \%$, gerando os maiores crescimentos. No entanto, as plantas apresentaram tendência de menor desenvolvimento vegetativo pelo aumento da luminosidade.

Verificou-se que a adição de nitrogênio, na forma de sulfato de amônio, não mostrou influência sobre o crescimento das plantas de erva-mate, nas condições do experimento, especialmente nos tratamentos a pleno sol e com $70 \%$ de luminosidade.

As plantas sem adição de nitrogênio apresentaram crescimento em altura superior ao daquelas com adição de nitrogênio, nos tratamentos com 50 e $30 \%$ de luminosidade, em todas as estações climáticas monitoradas. No entanto, nos tratamentos com 100 e $70 \%$ de luminosidade os resultados em crescimento foram equivalentes aos tratamentos sem e com adição de nitrogênio.

As melhores condições ambientais para incremento da produtividade de massa foliar foram verificadas nos tratamentos de luminosidades com 50 e $30 \%$. Entretanto, observou-se tendência de maior área foliar em plantas submetidas à luminosidade menor, com alterações morfológicas no sistema foliar.

\section{REFERÊNCIAS}

ASTHON, P. M. S.; BERLYN, G. P. Leaf adaptations of some Shorea species to sun and shade. New Phytologyst, v.121, p.587-596, 1992.

BOEGER, M. R. T.; ALVES, L. C.; NEGRELLE, R. R. B. Variações morfo-anatômicas dos folíolos de Tapirira guianensis Aubl. em relação a diferentes estratos da floresta. Biotemas, v.11, n.2, p.27-38, 1998.

R. Árvore, Viçosa-MG, v.31, n.4, p.619-627, 2007 
BOEGER, M. R. T. et al. Efeito das diferentes condições de luz e concentrações de nitrogênio sobre a estrutura foliar de Ilex paraguariensis $\mathrm{St}$. Hil. In: CONGRESSO SULAMERICANO DE ERVAMATE, 3.; REUNIÃO TÉCNICA DA ERVA-MATE, 4.,2003, Chapecó. Anais ... Chapecó: EPAGRI, 2003. CD-ROM.

BOEGER, M. R. T.; WISNIEWSKI, C. Estrutura e teores de nutrientes foliares de seis espécies arbóreas ao longo de um gradiente sucessional da planície litorânea do estado do Paraná, Brasil. Ilheringia. v.57, n.2, p.243-262. 2002.

CARVALHO, P. E. R. Espécies florestais brasileiras: recomendações silviculturais, potencialidades e uso da madeira. Colombo: Embrapa - CNPF; Brasília: Embrapa-SPI, 1994. 639p.

DA CROCE, D. M. \& FLOSS, P. A. Cultura da erva-mate no Estado de Santa Catarina... Florianópolis: EPAGRI, 1999. 81p. (Boletim Técnico, 100)

DA SILVA, V. P.; MAZUCHOWSKI, J. Z. Sistemas Silvipastoris - paradigma dos pecuaristas para agregação de renda e qualidade. Curitiba: EMATER, 1999. 52p.

EMPRESA BRASILEIRA DE PESQUISA AGROPECUÁRIA - EMBRAPA. Centro Nacional de Pesquisa de Solos. Sistema Brasileiro de Classificação de Solos. Rio de Janeiro: 1999. 412p.

ENGEL, V. L.; POGGIANI, F. Influência do sombreamento sobre o crescimento de mudas de algumas essências nativas e suas implicações ecológicas e silviculturais. IPEF, n.43/44, p.1-10, 1990.

FAHL, J. I.; CARELLI, M. L. C. Influência do sombreamento nas características fisiológicas envolvidas no crescimento de espécies de Coffea. In: SIMPÓSIO INTERNACIONAL SOBRE CAFÉ ADENSADO, 1994, Londrina. Anais ... Londrina: IAPAR, 1994. p.289-290.

FERREIRA, A. G.; ALMEIDA-CORTEZ, J. S.; CUNHA, G. G. Fisiologia de Ilex paraguariensis $\mathrm{St}$. Hil. com ênfase na embriologia experimental. In: REUNIÃO TÉCNICA DO CONE SUL SOBREA CULTURADAERVA-MATE, 1994. Porto Alegre. Anais ... Porto Alegre: FAPERGS, 1994. p.161-172.
FLOSS, P. A.; BOHNER, J. A. M.; DITTRICH, R. C. Estudo da longevidade foliar na erva-mate (Ilex paraguariensis St. Hil.). In: CONGRESSO SULAMERICANO DA ERVA-MATE, 2.; REUNIÃO TÉCNICA DO CONE SUL SOBRE A ERVA-MATE, 3., 2000, Encantado. Anais ... Encantado: UFRGS/FEPAGRO-RS, 2000. p.133-136.

FOSSATI, L. C. Avaliação do estado nutricional e da produtividade de erva-mate Ilex paraguariensis St. Hil., em função do sítio e da dioicia. 1997. 113 f. Dissertação (Mestrado em Ciências Florestais) Universidade Federal do Paraná, Curitiba, 1997.

GIBERTI, G. C. Ilex en Sudamérica: florística, sistemática y potencialidades con relación a um Banco de Germoplasma para la Yerba Mate. In: REUNIÃO TÉCNICADOCONE SULSOBREAERVA-MATE, 1995, Porto Alegre Anais ... Porto Alegre: Universidade Federal do Rio Grande do Sul, 1995. p.303-312.

KASPARY, R. Efeito de diferentes graus de sombreamento no desenvolvimento de plantas jovens de erva-mate (Ilex paraguariensis St. Hil.). 1985. 54f. Dissertação (Mestrado Botânica) - Universidade Federal do Rio Grande do Sul, Porto Alegre, 1985.

KRICUN, S. D. P. Yerba mate: investigación agronómica en la Republica Argentina. Cerro Azul: INTA, Estación Experimental Agropecuária de Misiones, $1983.16 \mathrm{p}$.

LOURENÇO, R. S. Adubação em erva-mate. In: CONGRESSOSUL-AMERICANODAERVA-MATE, 1.; REUNIÃO TÉCNICADO CONE SUL SOBREA ERVA-MATE, 2., 1997, Curitiba. Anais ... Colombo: Embrapa-CNPF, 1997. P. 299-315. (Documentos, 33).

MAZUCHOWSKI, J. Z. Incorporação e exportação de biomassa e de nutrientes pela erva-mate. Curitiba: UFPR/ EMATER, 2001. 28p.

MEDRADO, M. J. S. et al. Implantação de ervais. Colombo: Embrapa/Florestas, 2000, 26p. (Circular Técnica, 41)

NAKAZONO, E. M. et al. Crescimento inicial de Euterpe edulis Mart. em diferentes regimes de luz. Revista Brasileira de Botânica, v.24, n.2, p.173-179, 2001. 
OLIVEIRA, Y. M. M.; ROTTA, E. Área de distribuição natural de erva-mate (Ilex paraguariensis St. Hil.). In: SEMINÁRIO SOBRE ATUALIDADES E PERSPECTIVAS FLORESTAIS SILVICULTURA DA ERVA-MATE, 10, 1985, Curitiba. Anais...Curitiba: Embrapa-CNPF, 1985. p.17-36.

RAKOCEVIC, M.; MEDRADO, M. J. S.; TAKAKI, M. Aspectos fotomorfogenéticos de plantas jovens de erva-mate. In: CONGRESSO SULAMERICANO DA ERVA-MATE, 3.; REUNIÃO TÉCNICA DO CONE SUL SOBRE AERVAMATE,4., 2003, Chapecó. Anais ... Chapecó: 2003. CD-ROM.
REICH, P. B. Phenology of tropical forest: patterns, causes and consequences. Canadian Journal of Boatny, v.73, p.164-174, 1995.

SIMS, D. A.; PEARCY, R. W. Response of leaf anatomy and photosynthetic capacity in Alocasia macrorrhiza (Araceae) to a transfer from low to high light. American Journal of Botany, v.79, p.449-455, 1992.

VIEIRA, A. R. R. et al. Influência do microclima de um sistema agroflorestal na cultura da erva-mate (Ilex paraguariensis St. Hil.). Revista Brasileira de Agrometeorologia, v.11, n.1, p.91-97, 2003. 
